\title{
Using Modern Audit Methods to Overcome the Challenges Facing the Audit Profession in The COVID-19 Pandemic
}

\author{
Asmaa Abd El-monem serag \\ Lecturer of accounting - Faculty of commerce - Tanta university \\ asmaa.serag@commerce.tanta.edu.eg \\ Mona Mohammed Daoud \\ PHD of accounting - Faculty of commerce - Tanta university \\ monadaoud1980@gmail.com
}

\section{Introduction :}

The spread of the COVID-19 epidemic on a large scale in most countries of the world has led to the emergence of many effects in all fields, the most important of which are health, economic and social impacts (Ibrahim \& Zayed, 2020). Also, the Covid-19 pandemic has caused an increase in the level of uncertainty for business enterprises, which creates many difficulties and challenges as for managing these enterprises and preparing financial reports when evaluating the current and potential material effects of the Corona virus outbreak on financial reports ( Mahmoud \& Al-Tahan, 2020). The audit profession has also been affected by this crisis, as it does not work in isolation from the surrounding environment, and the greater the uncertainty associated with the business environment, the greater the challenges facing the audit profession to carry out its responsibilities.

In addition, there are many associated risks which are impacted by COVID-19, for example: cyber and fraud risks, reputation risks, supply chain risks, health \& safety risks. Some studies (Al-Jabali,2020 ; Deloitte,2020 ; KPMG, 2020) indicated that the precautionary procedures followed to deal with the crisis of the spread of the Corona virus in the world, such as social distancing and the application of the remote work system, had many effects, and the most important of these effects is increasing the risks associated with the use of electronic accounting information systems in business enterprises, as a result of the increase in the number of the information systems users, whether from its employees or from external parties such as customers and suppliers.

Those studies added that the exceptional circumstances and conditions resulting from the spread of the Corona virus also lead to an increased risk of electronic information systems being hacked due to weak and ineffective internal control procedures, which poses a threat to data security and confidentiality and increases the likelihood of its exposure to loss or distortion, and decrease the quality of the outputs of information systems. Therefore, the audit profession should keep pace with the development of the surrounding environment to face the continuous changes and developments in the business environment, and this requires a focus on using modern technology in data analysis and activating modern audit methods such as continuous auditing and remote auditing.

\section{Benefits of Using Modern Audit Methods during the COVID-19}

\section{Pandemic:}

The audit profession faces many challenges in light of the rapid global developments in the business environment, the most important of which is the technological revolution, and the crisis of the spread of the Corona virus ( Abdel- Aal, 2020). So, it becomes clear the importance 
of developing the method of performing the audit process during the Corona pandemic crisis, through applying modern audit methods, such as the remote audit approach, which relies on using information and communication technology to perform audit tasks efficiently, which enable auditors to provide the roles assigned to it and meet the needs of stakeholders, and overcome the challenges facing the audit profession during the period of the epidemic on the other hand.

Several studies (Alles, 2015; E\&Y,2015; Saleh \& Ahmed, 2017; Gepp et al.,2018; KPMG,2018 ; PWC,2018) have recommended increasing the reliance on technology and using modern methods and tools of auditing and data analytics in planning and implementing audit tasks, which contributes to better conclusions, reduces the costs of performing audit activities, excludes activities that do not add value to the enterprise, and enable auditors to expand their consulting services. These studies also concluded that using modern methods and tools of auditing achieves many advantages:

- Increase the speed and efficiency of the audit process - expanding the audit scope of and increasing audit coverage.

- Easy to identify data models and trends and relationships among them, and increase the ability to monitor risks.

- Saving time and efforts, and reducing the number of auditors needed to implement the audit programs.

- Increase the productivity of the audit team, and increase the quality of the services provided.

- Developing the services provided by audit firms, maintaining their competitive position and increasing their market share

And ( Abdel- Aal, 2020) added that the use of modern technological methods and tools in the practice of auditing work leads to saving time and effort of the audit team, enabling auditors to expand the provision of advisory services, increase diversity of audit firm services to provide the needs of stakeholders, and also contribute to achieving efficiency and reducing the costs of the audit process, and thus increase the profits of audit firms .

\section{Audit Methods that can be used to Face the Challenges of the COVID-19}

\section{Pandemic:}

\subsection{Remote Auditing :}

Within a few weeks of the start of the COVID-19 pandemic, the international audit community acted to provide a path forward for certification bodies, auditors, and certified companies: the expanded use of remote auditing. The process of remote auditing has been an option for QMS certification audits within the ISO 19011 standard, "Guidelines for auditing management systems." However, prior to 2020, remote auditing was infrequently used as a means of conducting the typical ISO 9001 audit (Picciotti, 2020).

Remote audit, also known as virtual audit, is the method of conducting an audit remotely, using electronic methods such as video conferencing, email and telephone to obtain audit evidence, just like auditors would during an on-site audit. The overall aim is to evaluate this evidence objectively to determine the extent to which the audit criteria has been fulfilled. Remote auditing provides a springboard for tools such as file and screen sharing, video conferencing (Skype and Zoom are common platforms), and live data 
analysis. During this type of audit, auditors are able to adopt standard auditing techniques which they use during on-site audits, but through using modern technology.

(Teeter et al.,2010) defines remote audit as " the process by which internal auditors couple information and communication technology (ICT) with data analytics to gather and assess electronic evidence, interact with the auditee, and report on the accuracy of financial data and internal controls, independent of the physical location of the auditor". And (ISO \& IAF,2020) added that Remote audits refer to the use of information and communication technology (ICT) to gather information, interview an auditee, when face-to-face methods are not possible or desired.

A remote audit is conducted partially or completely off site. Regardless of the chosen approach, which depends on audit objectives and requirements, the auditor will cover all what is usually covered on site but uses technology to collect data safely when a site visit is not possible or appropriate. So, there are two main approaches for conducting remote auditing (Tysiac, 2020) :

(a) Partial Remote Audit : Is conducted through a combination of remote and on-site procedures, the remote portion of the audit shall follow the standard course of an audit while using technological tools to access the necessary evidence.

Partial remote audits are most effective in verifying compliance with standard requirements which require documentary evidence. A limited set of interviews or other visual evidence will also be collected remotely. The on-site part of the audit is intended to verify the conclusions of the remote audit and conduct additional verification of issues that could not be detected through the remote auditing process.

(b) Full Remote Audit : Is conducted completely remotely using technology to gather information as necessary to confirm compliance with Standards. In cases where onsite verification is not realistically possible within the current audit cycle, a full remote audit will be necessary. Full remote audit should follow the standard course of an audit while using technological mechanisms and tools to access the necessary evidence, including interviews using appropriate sampling techniques.

The current COVID-19 crisis forces auditors to adjust traditional way of working and adapt new auditing techniques and optimizing the use of technology. Given the travel restrictions and employees being obliged to work from home, remote auditing is not an option anymore, It has become a necessity. Because of the fast advances in technology, conducting remote audits is becoming more popular among organizations. Businesses already include high-tech strategies that allow audit teams to receive and share data, conduct interviews, and make observations with organizations from all over the world without the need of commuting for several hours to the audit site.

Improvements in technology have enabled new ways of auditing remotely, one is videoconferencing technology, which gives auditors the ability to hold live interviews with clients and watch for visual cues that would be observed during a site visit. Many videoconferencing platforms also enable auditors to share documents on their screens for simultaneous viewing with others in the conference who are off-site. Secure web portals, meanwhile, are critically important for secure sharing of documents. Because of security considerations, email is viewed by experts as an unsafe way of sharing sensitive information such as financials and personal information about employees that auditors often examine.

In addition, information and communication technology (ICT) and analytics enable auditors to interact with other business process owners and team members, as well as gather and analyze data. The desired outcome is a location-independent audit where audit tasks can be performed by any auditor with a network connection, whether they are on-site or working remotely. auditors don't need to be physically present to conduct an entire audit no longer applies. Many audit tasks can now be led by virtual audit teams, and technology facilitates a 
reengineering of what auditors do and how they do it. For example, videoconferencing replaces travel to an audit location, which is reflected in the reduction of travel and transportation expenses.

The auditors also use automated tools to extract and analyze data from the enterprise's systems to test internal controls and transactions. As the cost of technology and online access continues to decline and budgetary pressure increases, more and more internal audit teams are using remote audit technology. Some additional motivators for organizations embracing a remote audit include improved audit quality, extended client contact time, increased perceived contact time, expanded audit coverage, and reduced travel expenses

Remote audit enables auditors to monitor transactions and communicate with business process owners throughout and subsequent to formal audit engagements. In a similar manner, when continuous auditing systems alert auditors to potential internal control weaknesses, fraud, or error, the auditors can respond remotely to help management resolve those issues

One of the benefits is the ability to allow auditors to receive and share data, review documentation and processes, conduct interviews and make observations with auditees from all over the world without the need to commute to the audit site. With the time spent commuting eliminated, auditors can also spend more time doing things that add value, such as reviewing documentation to ascertain which audit trails to explore, and spending time writing audit reports to a higher standard that clearly outline audit outcomes such as findings opportunities for improvement.

Another potential benefit of remote auditing is that audit efficiency can be achieved through the reduction of latency, which occupies labor and capital (Teeter et al. 2010). Latencies occur in all business processes, particularly the audit process, through engagement procurement, audit planning, internal controls evaluation, internal controls compliance, and substantive testing, all experience significant intra- and inter-process latencies during audit task performance and auditor meetings. Audit decisions and reporting face decision and outcome latency as auditors work with managers to address and resolve issues. Latency reduction for any of these subprocesses can free up resources, especially auditor labor, to be utilized elsewhere.

The utilization of technology to carry out audits remotely also saves time and money. Data can be accessed from anywhere, such as a cloud portal. Auditees are also likely to be more engaged in the process if a set time is allocated for remote audit activity. They are less likely to be sidetracked or disturbed with any urgent work requests, including answering emails, telephone calls and dealing with queries from fellow staff members. Remote auditing can give the opportunity for a different approach and outlook, adding value to both auditor, auditee, and the overall audit process.

Remote audit free up onsite resources, are less disruptive to workflow and support maximized efficiency by allowing audit teams to work from familiar offsite locations. Logistical support is limited to the installation and maintenance of technology and tools, and the use of securityenhanced cloud computing, document sharing and video conferencing applications promotes an agile and more responsive auditing process. In addition, the use of ICT allows for the inclusion of expertise in an audit that otherwise might not be possible due to financial or logistical constraints. With ICT available participation of the technical expert may be able to analyze the process remotely, thereby reducing time and costs associated with travel.

Also, there are several reasons why conducting remote audits can be beneficial for companies and internal auditors (IIA, 2020 ; Kashyap, 2020 ; KPMG, 2021) :

- Saving time and money by using technology: Most of data is accessible from anywhere, such as a cloud portal, so there is no need to waste much time and cost to travel for checking documentation. By using remote auditing, there will be a significant reduction in time and cost spent on travelling to the audit locations. In addition, interviews and observations can 
be conducted through popular platforms like Skype or Zoom, which are regularly used by many of the companies already.

- Avoiding traveling to difficult audit locations: Some locations can be difficult to access for many reasons; maybe they are in an isolated area, or strict permits are needed to get in - even visas sometimes are required if audits are conducted internationally. With a remote audit, auditors can avoid these difficulties.

- Expanding audit coverage: Remote audits allow for more coverage when competing priorities of volume and time limitations occur.

- The audit team will be more efficient : Working from their home office environment, the audit team will feel more comfortable, since they will be able to use all the necessary tools, such as high-speed internet, monitors, printers, etc. This way, the productivity will be substantially increased and the audit team will need fewer hours to complete audit tasks and keep on schedule.

- Expand using of specialists: Specialists can connect remotely for selected interviews or parts of audit planning, and they need not be present for a full audit.

- More flexible approach improves document reviews: Remote reviews of plans and documentation, at the auditor's own pace, contribute to a higher quality review and a deeper dive into the documentation.

- Improved use of available technology strengthens documentation and reporting: Using technology to capture video and photographic information contributes to improving their understanding and use of available technology. This contributes to better documentation of facility conditions, improved ability to report incidents and conditions to remote corporate personnel, and increased opportunities for future remote training tools.

- Logistics related to auditing are not needed anymore: When conducting remote audits, usually organizations are relieved from logistics related to booking conference rooms and cleaning after the audit team leaves, as well as worrying about audit team accommodation, interruptions to employees' regular workflow, and other related inconveniences experienced during an onsite audit.

\subsection{Continuous Auditing (CA):}

One of the key developments in modern audit methods is the concept of continuous auditing. Continuous Auditing, broadly defined as the transformation of internal and external auditing through the application of modern information technology, is being increasingly adopted by firms throughout the world. CA is technology-enabled auditing which produces audit results simultaneously with, or a short period of time after, the occurrence of relevant events. In comparison with the traditional financial statements audit, Continuous Auditing is more timely, comprehensive, accurate and less costly.

The American Institute of Certified Public Accountants (AICPA,2015) defined continuous auditing as "an organized process of collecting and evaluating electronic evidences as a reasonable basis for expressing an impartial technical opinion on the extent to which information and financial reports prepared by means of an immediate and paperless accounting information system". Continuous auditing can also be defined as "a methodology that enables auditors to provide Confirmation about the occurrence of an event immediately or shortly after its occurrence, which enables the auditors to respond promptly to changes in the events related to the facility, evaluate them and provide assurances about them ( Vasarhelyi et al.,2012).

Continuous auditing depends on using modern technology to detect errors in operations and data in real time, according to predefined indicators, and aims to provide an instant assurance as possible. Also, continuous auditing depends on defining clear objectives 
for the most important processes and controls that need to be analyzed and evaluated on an ongoing basis, as well as identifying indicators to measure their efficiency, as they rely heavily on the presence of the appropriate technology for them and also on data analysis ( Zhang et al., 2015).

The essential benefit of continuous auditing is that it decreases the latency between management operations and the provision of assurance. In the past managers had access to data that was far more detailed and obviously timelier than the auditor, who came into the picture only at the year's end. But the technology that underlies CA, especially ERP systems, allows auditors to see the same data as managers and at the same time-or even earlier, given their expertise in process monitoring. This has profound implications for whether auditing is seen as a device for ex-post verification or as a means of real-time monitoring. What is clear is that CA will lead to auditors having access to streams of data that they never could obtain costeffectively before and audit methodologies will have to adapt to this explosion in the magnitude, level of disaggregated detail and timeliness of data.

CA extends the analytical methods of traditional auditing by examining continuous flows of data, with models of system behavior used to establish expectations for data content. Monitoring the content of a firm's data flow focuses on examining both exceptional transactions and exceptional outcomes of expected transactions. CA software will continuously monitor company transactions, comparing their generic characteristics to observed/expected benchmarks, thus identifying anomalous situations. When significant discrepancies occur, alarms are triggered and are routed to the appropriate stakeholders (Alles et al.,2006).

So, while continuous auditing softens the timing constraint of the audit, remote auditing softens the location constraint. Implementing remote auditing may cause auditors to fundamentally rethink the manner in which an audit is carried out and the way the audit team is formed and managed. In order to realize the benefits of these modern audit methods, all interested parties should be aware of their role in the process, inputs, expected outputs, and risks and opportunities that will provide the basis to achieve the audit and audit program objectives.

\subsection{Big Data Analytics (BDA) :}

Huge amounts of data are generated on a daily and continuous basis as a result of the trend towards accelerated digital transformation, and this data is stored after processing it in huge databases, and this enormous information can be used to help decision-makers in the various departments and activities of the enterprise, by classifying this information and Analyzing them and extracting the indicators and deviations that reveal the weakness and strength in every activity, in addition to discovering the indicators of fraud by analyzing the irregular behavior of the data and operations, and analyzing the data enables the internal auditor to expand the scope of work and reduce effort, time and cost, and increase the efficiency of internal audit work.

The American Institute of Certified Public Accountants (AICPA,2017) defined data analytics as " the science and art of discovering and analyzing patterns, identifying anomalies, and extracting other useful information in the data underlying or related to the subject matter of an audit through analysis, modeling, and visualization for planning or performing the audit". Many studies ( Cao et al., 2015 ; Earley, 2015 ; Alles et al., 2016 ; IAASB, 2016 ; Rose et al., 2017; Dagilienè and Klovienè ,2019) concluded that using data analytics will improve financial statement audits because: 
(1) Auditors can test a larger number of transactions, however auditors can use digital tools to evaluate all data of the firm and no longer use the sampling method.

(2) Audit efficiency will be improved by offering more insight into the processes of the enterprise.

(3) Digitalization of audit processes enable auditors to improve risk assessment and quality of judgments by identifying the abnormalities and by proposing solutions to issue highlighted.

(4) Auditors could also focus on current data, and not just historical information, to give a prospective vision of the firm ,this additional analysis could significantly enhance the audit relevance and improve the corporate governance, and fraud would be easier to detect.

Other studies (Brown et al., 2015 ; Bende, 2017 ; Rose et al., 2017; Manita, 2020) focused on the beneficial effect of Big Data Analytics (BDA) tools in improving the quality of the audit process and adding value for stakeholders through improving audit efficiency and effectiveness. Moreover, these studies concluded that using BDA and new digital tools will be necessary and enlarge the sufficiency, reliability, and relevance of audit evidence, which increase the audit quality.

Also, big data analytics can help auditors in conducting a comprehensive review of all operations instead of reviewing using samples, which contributes to identifying key areas of risk, improving the risk assessment process, especially fraud risks, and providing additional analyzes helps in achieving a better understanding of various aspects of customer activity and improving judgments, which contributes to improving the quality of audit services.

\section{4- Conclusion :}

The COVID-19 pandemic has led to the emergence of many effects in all fields, and creates many difficulties and challenges for the audit profession. So, auditors should keep pace with the development of the surrounding environment to face the continuous changes and developments in the business environment, and this requires a focus on using modern technology in data analysis and activating modern audit methods such as continuous auditing and remote auditing.

The COVID-19 pandemic has spurred the adoption of remote audits in organizations across the world, but subsequent time and costs savings suggest remote auditing will remain popular into the future. Adopting communications and analytic technology to extend the scope, change the timing, and reduce the costs of audit processes. enable auditors to work remotely, reduce travel costs and latency, and increase efficiency and coverage.

Also, continuous auditing could be used to detect errors in operations and data in real time, according to predefined indicators, and aims to provide an instant assurance as possible. Continuous auditing depends on defining clear objectives for the most important processes and controls that need to be analyzed and evaluated on an ongoing basis, as well as identifying indicators to measure their efficiency, as they rely heavily on the presence of the appropriate technology for them and also on data analysis. The essential benefit of continuous auditing is that it decreases the latency between management operations and the provision of assurance.

So, while continuous auditing softens the timing constraint of the audit, remote auditing softens the location constraint. Implementing remote auditing may cause auditors to 
fundamentally rethink the manner in which an audit is carried out and the way the audit team is formed and managed. In order to realize the benefits of these modern audit methods, all interested parties should be aware of their role in the process, inputs, expected outputs, and risks and opportunities that will provide the basis to achieve the audit and audit program objectives.

Also, using big data analytics can help auditors in conducting a comprehensive review of all operations instead of reviewing using samples, which contributes to identifying key areas of risk, improving the risk assessment process, especially fraud risks, and providing additional analyzes helps in achieving a better understanding of various aspects of customer activity and improving judgments, which contributes to improving the quality of audit services.

\section{And based on the above, the researchers recommend the following:}

1- Provide the necessary investments and financial resources to get modern technology, and develop the skills and expertise of auditors in dealing with modern audit methods and tools through training programs.

2- Increasing reliance on the use of modern technology in data analysis and activating modern audit methods such as continuous auditing and remote auditing to overcome the restrictions imposed by social distancing procedures and the application of the remote work system.

3- Increasing the qualifications and practical experience of auditors in the area of crisis and disaster management, and asking for help of some specialized experts in some aspects when audit team don't have the sufficient experience.

4- Auditors should design and implement additional and non-traditional audit procedures to obtain sufficient and appropriate evidence, and use modern means of communication Such as Zoom, Skype, and video conferencing To achieve continuous communication between audit team, exchanging information and observations, and discussing the results that have been reached up to date.

5- Auditors should apply a high level of professional skepticism, and rely on personal judgment during all stages of the audit process to overcome the fundamental uncertainty associated with the COVID-19 crisis.

6- Egyptian accounting and auditing standards to include guidelines for measurement and disclosure during crises and disasters, in addition to provide adequate guidance to auditors to help them providing high quality audit services under exceptional circumstances.

\section{References :}

- Al-Jabali, Walid Samir Abdel-Azim 2020. The impact of the spread of the Coronavirus COVID-19 pandemic on preparing and reviewing financial statements - a field study. The Scientific Journal of Accounting Studies, Issue 1, 1145-1205.

- Abdel-Aal, Yasmine Kamel Ibrahim. 2020. The future of the auditing profession in Egypt and the implications of global developments on it to increase the effectiveness of its role in the Egyptian economy. Conference of Accounting and Auditing Department, Faculty of Commerce - Alexandria University. 
- Alles, M.A., Brennan, G., Kogan, A., and Vasarhelyi, M.A. 2006. Continuous Monitoring of Business Process Controls: A Pilot Implementation of a Continuous Auditing System at Siemens. International Journal of Accounting Information Systems, Vol 7. 137-161.

- Alles, M. G. 2015. Drivers of the use and facilitators and obstacles of the evolution of Big Data by the audit profession. Accounting Horizons, 29(2), 439-449.

- Alles, M., and Gray, G. L. 2016. Incorporating big data in audits: Identifying inhibitors and a research agenda to address those inhibitors. International Journal of Accounting Information Systems, 22, 44-59.

- American Institute of Certified Public Accountants (AICPA). 2015. Audit Analytics and Continuous Audit : Looking Toward the Future. New York, USA

- American Institute of Certified Public Accountants (AICPA). 2017. Guide to Audit Data Analytics. New York, USA.

- Bende T. 2017. The effect of data analytics on audit efficiency, Erasmus university Rotterdam, https://www.semanticscholar.org/paper

- Brown-Liburd, H., Issa, H., and Lombardi, D. (2015). Behavioral implications of Big Data's impact on audit judgment and decision making and future research directions. Accounting Horizons, 29(2), 451-468.

- Cao, M., Chychyla, R., and Stewart, T. (2015). Big Data analytics in financial statement audits. Accounting Horizons, 29(2), 423-429

- Dagilienè, L., and Klovienè, L. 2019. Motivation to use big data and big data analytics in external auditing. Managerial Auditing Journal, 34(7), 750-782.

- Deloitte .2020. Delivering remote internal audits responding to COVID-19. Available at : www.Deloitte.com.

- Earley, C. E. 2015. Data analytics in auditing: Opportunities and challenges. Business Horizons, 58(5), 493-500.

- Ernst \& Young (E\&Y) .2015. How big data and analytics are transforming the audit. Retrievedfrom:https://www.ey.com/en_gl/assurance/how-big-data-and-analytics-aretransforming -the-audit

- Gepp, A., Linnenluecke, M. K., O’Neill, T. J., and Smith, T. 2018. Big data techniques in auditing research and practice: Current trends and future opportunities. Journal of Accounting Literature, $40,102-115$.

- Ibrahim, Mohamed Zidan and Mohamed Abdel Moneim Zayed 2020. The accounting implications and implications of the Coronavirus (COVID-19) crisis - An analytical view from an accounting perspective. Alexandria Journal of Accounting Research, Faculty of Commerce - Alexandria University, 4(2) ,1-28.

- International Auditing and Assurance Standards Board (IAASB). 2016. Request for input: Exploring the growing use of technology in the audit, with a focus on data analytics. Retrieved from: $\quad \underline{\text { https://www.ifac.org/system/files/publications/files/IAASB-Data-Analytics-WG- }}$ Publication-Aug-25-2016-for-comms-9.1.16.pdf

- International Organization for Standardization(ISO) \& International Accreditation Forum (IAF) .2020. ISO 9001 Auditing Practices Group Guidance on: Remote Audits. Available at : www.iso.org.

- Kashyap ,Vinod .2020. Remote Audit During and Beyond COVID-19. The 50 $0^{\text {th }}$ World Continuous Auditing and Reporting Symposium. November 6 \& 7, 2020. 
- KPMG. 2020. COVID-19: The Impact on Internal Audit. March 2020. Available at : www.KPMG.com .

- KPMG .2021. Remote Auditing for Internal Auditors. Available at : www.KPMG.com

- Mahmoud, Abdel-Hamid Al-Essawi and Ibrahim Mohamed Al-Tahan. 2020. The implications of the Covid-19 pandemic on the environment and activities of the external audit with an exploratory study of the reality of the Egyptian professional practice environment. Alexandria Journal of Accounting Research, Faculty of Commerce - Alexandria University, 4(2), 448-535.

- Manita, R., Elommal, N., Baudier, P., \& Hikkerova, L. 2020. The digital transformation of external audit and its impact on corporate governance. Technological Forecasting and Social Change, $150,119751$.

- Picciotti, Daniella .2020. Remote Auditing: An ISO 9001 Auditor's Perspective. Retrieved from: https://www.theauditoronline.com/remote-auditing-an-iso-9001-auditors-perspective/ .

- PriceWaterhouseCoopers (PWC) .2018. Moving at the Speed of Innovation : The Foundational Tools and Talents of Technology-enabled Internal Audit, Available at : www.pwc.com/internalaudit .

- Rose, A., J. Sanderson, K. and Thibodeau. 2017. When should audit firms introduce analyses of big data into the audit process?. Journal of Information Systems, 31(3), 81-99.

- Saleh, Samir Abul-Fotouh and Samah Tariq Ahmed. 2017. The impact of the integration of modern tools and techniques to increase the efficiency of internal audit. The Scientific Journal of Commercial and Environmental Studies, Ismailia faculty of Commerce - Suez Canal University, 8 (3), 710-750.

- The Institute of Internal Auditors (IIA) .2020. Remote Auditing for COVID -19 and Beyond : Short-term and Long-term Implications. Available at: www. theiia .org

- Teeter, Ryan A. , Michael G. Alles, Miklos A. Vasarhelyi . 2010 .The Remote Audit . Journal of Emerging Technologies in Accounting, Vol. 7, 73-88.

- Tysiac, Ken. 2020. Remote auditing comes to forefront during pandemic. Journal of Accountancy. Online Issue. Retrieved from https://www.journalofaccountancy.com/news/2020/mar/remote-auditing-during-coronaviruspandemic.html.

- Vasarhelyi, M. , M. Alles, S. Kuenkaikaew, and J. Littley. 2012. The acceptance and adoption of continuous auditing by internal auditors. Journal of Accounting Information Systems Researches. 13( 3), 267-281.

- Zhang, J., Yang, Y. and D., Appelbaum, D. 2015. Toward effective Big Data analysis in continuous auditing. Accounting Horizons, 29(2), 469-476. 